\title{
The Illusions of the Modern Synthesis
}

\author{
Denis Noble ${ }^{1}$
}

Received: 1 December 2020 / Accepted: 1 March 2021 / Published online: 26 March 2021

(C) The Author(s) 2021

\begin{abstract}
The Modern Synthesis has dominated biology for 80 years. It was formulated in 1942, a decade before the major achievements of molecular biology, including the Double Helix and the Central Dogma. When first formulated in the 1950s these discoveries and concepts seemed initially to completely justify the central genetic assumptions of the Modern Synthesis. The Double Helix provided the basis for highly accurate DNA replication, while the Central Dogma was viewed as supporting the Weismann Barrier, so excluding the inheritance of acquired characteristics. This article examines the language of the Modern Synthesis and reveals that it is based on four important misinterpretations of what molecular biology had shown, so forming the basis of the four Illusions: 1. Natural Selection; 2. The Weismann Barrier; 3. The Rejection of Darwin's Gemmules; 4. The Central Dogma. A multi-level organisation view of biology avoids these illusions through the principle of biological relativity. Molecular biology does not therefore confirm the assumptions of the Modern Synthesis.
\end{abstract}

Keywords Modern synthesis · Neo-Darwinism · Natural selection · Weismann barrier · Darwin's Gemmules · Pangenesis · The central dogma $\cdot$ Biological relativity

\section{Introduction}

Biosemiotics is the study of signs that can be the basis of the production of meaning by living organisms. It necessarily involves study of the communicative methods used interpreting communication in the widest sense, including signs and their contexts used by non-human organisms.

The focus in this article however, is on human communication: specifically the ways in which biological scientists describe their experimental results and their interpretations of those results. I will discuss the relevance to and from the study of pre-linguistic meaning at the end of the article (see Relevance to biosemiotics).

Denis Noble

Denis.noble@dpag.ox.ac.uk

1 Department of Physiology, Anatomy \& Genetics, University of Oxford, Oxford, UK 
The problem that I will highlight is that the language used in biology during the second half of the twentieth century is misleading in relation to the question of meaning. In Dance to the Tune of Life: Biological Relativity (Noble 2016, pp. 138152), I devoted most of one chapter to an analysis of words and expressions like 'gene', 'The Selfish Gene', 'The Book of Life', 'the genetic code', 'genetic program', 'blueprint', 'replicator', and 'vehicle'. I concluded that "all parts of the Neo-Darwinist discourse encourage the use and acceptance of the other parts." It is for that reason difficult to break out from its attractive simplicity.

In this article I take that study further to identify more precisely why this is the case. I have chosen to do so by unravelling the development of what I call the four illusions of the Modern Synthesis. I then describe a principle by which these illusions can be avoided.

It may be hard to believe that science itself could be taken in by illusions and by its own use of language. Yet, that is precisely what I think happened in the development of the Modern Synthesis. This is not an accusation of intended illusion. I believe all the distinguished scientists involved were genuinely convinced of their facts and theories. But we can all be taken in by our culturally-inherited illusions without realising that is what they are. Metaphors and analogies can become linguistically 'dead' (Lakoff and Johnson 1980) so that we come to think of them as literal. Human languages are full of dead metaphors and similes, which is why they are also full of conceptual traps. In the case of "the Selfish Gene" (Dawkins 1976, 2016), its author, Richard Dawkins, even stated initially that he thought it was "the literal truth" (Dawkins 1981). I don't think he believes that now.

It is important therefore to understand that I am not accusing anyone of deliberately trying to mislead people. All the people involved are leading scientists. My argument is that language itself contained the seeds of the problem. That makes it even more important to re-examine the language of biology. The four illusions are: 1. Natural Selection; 2. The Weismann Barrier; 3. The Rejection of Darwin's Gemmules; 4. The Central Dogma.

\section{The Modern Synthesis and its Evolution}

First, what is the Modern Synthesis? Historically, it developed from the fusion of neoDarwinism with Mendelian genetics and was formulated in the 1930s and 1940s, culminating in Julian Huxley's (1942) book, Evolution: The Modern Synthesis. Its greatest populariser is Richard Dawkins, notably in The Selfish Gene (Dawkins 1976), but also in many other books by him.

Neo-Darwinism owed its origin in the later nineteenth century to Wallace and Weismann. Wallace removed sexual selection as a separate process from natural selection in Darwin's work, while Weismann removed the inheritance of acquired characteristics. It therefore became a severely slimmed down version of Charles Darwin's ideas. The fusion with discrete inheritance in Mendelian Genetics occurred after 1900. The terms Neo-Darwinism and Modern Synthesis are often used interchangeably. The Modern Synthesis developed before the great discoveries of molecular biology and the formulation of the Central Dogma, but many saw those discoveries as confirming the Modern Synthesis. Another way of viewing my article is to show that 
this cannot be true. In fact the major discoveries of molecular biology undermined the Modern Synthesis, even though that was not appreciated at the time.

Since its original formulation there have been proposals to extend the Modern Synthesis: the Extended Evolutionary Synthesis, EES (Pigliucci and Müller 2010, see also the articles in a previous issue of this journal (Winters 2018), or to replace it with a more radical integrative (Noble 2016, chapter 8) or inclusive (Corning 2020) evolutionary synthesis, sometimes called the EIS. The differences between these two approaches, to extend or replace the Modern Synthesis, are analysed in Noble (2016, pp. 232-236). The illusions to which I refer stem from the original 1942 Modern Synthesis, as they are presented in textbooks and popularizations even today (e.g. Coyne 2009; Dawkins 1976, 2016; Futuyma \& Fitzpatrick, 2018). A forthcoming analysis shows the absence of any acknowledgement of the problems to which I refer (Shapiro and Noble 2021). Where relevant I will note how my analysis affects these ideas.

\section{Illusion 1. The Different Forms and Meanings of 'Selection'}

Charles Darwin (1859) introduced the idea of natural selection (a non-intentional filter) as a metaphorical comparison with artificial (intended) selection. There is no actual selection carried out by natural 'selection'. Nature - in this case the different rates of survival - is simply a passive filter. Yet it is often presented as the active driver of evolution.

There are active drivers of evolution, to which I will return later, but it is an illusion to think that 'blind' natural selection is really 'selecting' or could be an 'active' driver. It is an illusion with important consequences because it can lead people to think that real selection, by organisms themselves with the power to do so, cannot even exist. This view is expressed most notably by Jerry Coyne (2014) when he argues that evolution has "bequeathed us such a powerful illusion [of agency]". That idea is itself an illusion generated by a conceptual mistake, which is to confuse the metaphor of selection with reality. If all evolutionary change is produced by natural (unintended) selection, then no organisms can have the power of real, intended selection. As I have already noted, this move to exclude genuine agency was first made in the nineteenth century by Alfred Russel Wallace, leading him to disagree with Darwin's distinction between natural and artificial selection.

Darwin however was quite clear about the difference. He wrote in his 1871 book (Darwin, 1871):

"Just as man can give beauty [in his breeding of animals] ....so it appears that female birds in a state of nature, have by a long process of selection of the more attractive males, added to their beauty." (The Descent of Man, Penguin classics, p 246).

On the previous page (245) he makes it clear he means conscious choice: "and consciously exert their mental and bodily powers."

Some modern evolutionary biologists chide Darwin for his "quaint anthropomorphic descriptions" (Coyne 2009, p 175). As a physiologist I don't accept that. Consciousness and the neural structures that support it and the capacity to make intentional choices are great consumers of energy. Their evolution required payback in terms of selective advantages, which I believe the nervous system has given us. Consciousness, like life 
itself, must be functional to justify its cost. I therefore prefer the thesis of Ginsburg and Jablonka (2019) in their magisterial Evolution of the Sensitive Soul: Learning and the origins of Consciousness. Conscious processes evolved because they serve a purpose. As that book and one of their prior articles (Ginsburg and Jablonka 2010) argues, this development may even have been one of the drivers of the Cambrian Explosion. If so, one of the most important transitions in evolution was actually driven by organism agency, not by natural selection. And we are now in the middle of a further example of this process in what is called the anthropocene. We humans are now intentionally driving a major evolutionary transition (Corning 2020). It is ironic that the denial of our own intentionality may also become our own undoing if the anthropocene leads to our demise as a species. It can be argued, as Kalevi Kull (2018) has done, that the fundamental divide between the Modern Synthesis and its opponents is whether organisms have agency or whether "the relationship between phylogenetic and individual memory is a one-way road from the phylogenetic to the individual memory and not vice-versa" (Menzel 2003).

I think Darwin was right and was brilliantly foresighted to resist Wallace's attempt to subsume intentional sexual (and by implication other forms of social) selection to natural selection. Brilliant because I think he must have been aware of the importance of the distinction he was making. He did not use the word agency, but I think he would have agreed with biosemioticians that the concept is necessary to understand the meanings organisms give to the signs and communicative paradigms they use (Tønnessen 2015a).

The stakes of whether or not artificial selection exists and is mediated by intentional choice could not matter more to our own future: our choice will decide if we survive the great anthropocene extinction. It is down to us humans to decide whether we take the steps required to halt the great extinction of species that is now well under way as a consequence of our own actions and their impact on the natural world. Whether we survive will depend on whether we succeed in preserving enough of the world's flora and fauna, and their crucial diversity, to continue to support our own species.

The points made in this section have some features in common with the issue of identifying the units of selection, whether genes, organisms or groups of organisms. Below a certain level of organisation, the issue of intentional artificial selection does not even arise. Genes, for example, or any other molecules, certainly cannot carry intentionality. Organisms and groups of organisms do that.

\section{Illusion 2. The Weismann Barrier}

We owe the next illusion to August Weismann who argued that characteristics developed during the life of an organism could not be inherited by its progeny. So far as I know, the only experiments that Weismann performed to test his idea was to show that mice with amputated tails still had descendants with tails (Churchill 2015; Normandin and Wolfe 2013, p 282). The illusion here is that this disproves what the French biologist, Jean-Baptiste Lamarck, thought. But Lamarck didn't think that at all! That is a straw man in this case. What he really thought was that changes developed during life that were a functional advantage to an organism could be inherited precisely because they were a functional advantage. The way to test that idea was pioneered by Conrad 
Waddington over 50 years ago (Waddington 1957, 2014), as I argued recently (Noble 2016, pp. 216-219).

Surgical amputations just don't cut it (apologies for the pun), nor did Weismann think that his tail-cutting experiments established more than showing that surgical mutilations are not inherited (Noble 2016, p. 128). For functional evolutionary reasons the mice need their tails!! Animals with tails use them, for example for balance, as birds, monkeys and squirrels demonstrate. Cats and dogs use their tails to convey emotions. Furthermore, it would be tragic if accidental damage to their parents' bodies were to be frequently inherited by children. Just imagine if all broken bones, kidney failures, poor circulations, cancers and goodness know what else were automatically inherited. Thankfully, most of the time nothing like this happens.

Actually, sometimes they do. Accidental fatal mutations are just such. But, fortunately, those are very rare. They are the causes of the few diseases that have very strong correlations with a particular gene or a very few genes. Physiologists have also found a number of inherited health problems that are not genetic (Gluckman and Hanson 2011). The effects of long periods of starvation can be detected through several generations in humans (Heijmans et al. 2008) and in animals (Rechavi et al. 2014).

It is worth noting here that understanding the illusion of the Weismann Barrier is important to extensions/replacements of the Modern synthesis, the EES or EIS referred to in the Introduction. Both seek to include trans-generational epigenetic inheritance in evolutionary theory. That transgresses a foundational feature of the Modern Synthesis, which was based on combining the Weismann Barrier with Mendelian genetics. In that form the Modern Synthesis is incorrect.

\section{Illusion 3. The Debunking of Darwin's Theory of Gemmules}

Charles Darwin was a slow but deep thinker. Since he thought, like Lamarck, that functional changes in organisms could be inherited, he realised that, in organisms with a separate germ-line (actually such organisms are only a small minority of forms of life on earth - plants and micro-organisms don't need this), there would need to be some way in which the changes in the body could influence the cells that would become eggs or sperm. Darwin's problem was very similar to that of William Harvey who, 200 years earlier in 1628, proved the existence of the circulation. He had to suppose that something existed (he called them anastomoses or porosities in the flesh) to carry blood from the arteries through the tissues to the veins. It took 33 years before Malpighi in 1661 used the development of the light microscope so that capillaries could actually be seen.

Darwin used a similar logic to Harvey. He supposed that very tiny particles in the body, which he called gemmules (Darwin 1868), could communicate between the body and the germline. Even if what he supposed could not be seen, they might still exist.

\section{Must it Always Be Visible to Exist?}

It is a potential illusion to suppose that something required by a valid scientific theory does not exist simply because we can't see it. If we always took that view in physics, we would never have discovered electrons, protons and neutrons, and we certainly 
would not have discovered quarks and the Higgs Boson. We can't see magnetic fields but we do see their effects and are confident that they exist. Actually, this is true for our vision too. We do not 'see' the trillions of photons hitting our light-sensitive molecules. We 'see' our integrated interpretation of those effects. All perception is to some extent also an illusion. Professional magicians exploit this fact.

We anticipate much of what we think we see. Anticipation is of great evolutionary significance (Simmers 2016). It endows conscious beings with a competitive edge e.g. in predator-prey interactions.

Of course, in the mid nineteenth century Darwin could not show that gemmules exist. The resolution of the light microscope was not good enough in his time. Later, when the much higher resolution electron microscope was invented it became possible to see the very small, but numerous, particulate matter that surrounds all cells. This matter was first thought to be just rubbish, detritus extruded by cells. There was no way that could be checked. What we view in an electron microscope is a very thin section of dead tissue.

Then came a remarkable order of magnitude increase in the resolution of the light microscope. Using a clever way of getting molecules themselves to emit fluorescent light and to know what and where those molecules are, we are now able to see what we call extracellular vesicles (EVs, sometimes also called exosomes) pouring out of living cells. They are little packets of chemicals including DNAs and RNAs that give a snapshot of the regulatory state of the cells from which they come. Other cells in the body can receive this information, which can then influence their behaviour. The implications of this discovery for evolutionary biology are profound. They form another system of communication between cells in the body, with consequences for biosemiotics. Just as we had to determine which parts of the genome are meaningfully used and which might be mere data, so we will need to determine which components of extracellular vesicles are actually used for communication. That question is also important clinically since EVs can be markers of many disease states (Edelstein et al. 2019).

Are they Darwin's gemmules, communicating with the germline? Well, they can pass straight through Weismann's so-called barrier and carry their information to the germ cells. That has been shown experimentally (Lavitrano et al. 2006; Cossetti et al. 2014; Chen et al. 2016; Spadafora 2018). That transmission automatically influences the behaviour of the resulting organism.

All of this is precisely what Darwin supposed (Noble 2019). If he were alive today he would be celebrating the vindication of his 1868 idea. So also would Lamarck with his idea of "subtle fluids". He would just need to admit that the "fluid" is particulate. There is now therefore a wide-open field for research into which processes of transmission of acquired characteristics use this method. I predict that there will be whole army of doctoral theses to be written on this question. Research on exosome communication is already of great clinical importance (Edelstein et al. 2019).

So I think that the Weismann Barrier is also an illusion, at least as it is used in evolutionary biology to exclude communication between the body and the germ-line.

\section{Barriers and Boundaries}

Actually, physiologists like me are extensively experienced in the permeability of physiological barriers. There are many others that have turned out to be illusions, 
notably the blood-brain barrier, which stops mainly pathogens from crossing into the brain. All these barriers are really boundaries (Noble et al. 2019), which means places where the organism determines what can pass and what can't. In other words these are functional parts of the organism that are highly regulated. It is confusing to call them barriers. They are not there to keep everything from crossing them. We would not even be alive if they did. Living organisms have to be able to control what enters and leaves them, and what can cross various boundaries within the organism.

This may be the reason why many physiologists have found the Weismann Barrier difficult to imagine as really stopping everything from crossing from the body to the germ-line. All the other barriers we know in the body are permeable - just to what the body needs to cross them. Organisms consist of nested levels of organisation with meshing of forms of causation between them.

\section{Illusion 4. The Illusion of the Central Dogma}

The Central Dogma of Molecular Biology has a claim to be the greatest illusion ever created in biology. It is so important and, as its name suggests, central to neo-Darwinist thought, that we need to take great care in revealing what creates the illusion. First let's summarise what is not illusory.

Molecular biologists from Watson and Crick onwards have unambiguously shown that DNA sequences can be used as templates to enable proteins to be formed. They do so via a triplet (3 DNA bases) coding for a single amino acid in a protein. But the reverse never happens. Amino acid sequences can never be used to create a new DNA sequence. That is one of the greatest established facts in modern biology.

All of that is absolutely correct. And I am not going to challenge any of those facts.

Yet those facts cannot have prevented cells and organisms from changing their own DNA when they need to, and when those changes can be functional. Which is precisely what Lamarck, and Darwin following him, also thought: that functional changes could be inherited. One of the mechanisms by which that can be achieved is natural genetic engineering (Shapiro 2011). During the course of evolution large domains of proteincoding DNA have moved around, leading to accretion of functionality to the proteins involved. I have described this process in further detail in Dance to the Tune of Life (2016, chapter 7, Fig. 7.4).

So how do we reconcile these two sets of apparently contradictory facts?

That can be done only by realising that there is a very deep illusion here. The illusory straw man was built in stages by various people at different times. I don't think any one of them fully intended the complete illusion. Each step became fully embedded in the standard story until it was no longer questioned. A metaphor (this is like that) became taken to be literal (this $i s$ that). The stages span many years so I will explain what happened in four steps.

\section{Step 1. Schrödinger and "What is Life?"}

Erwin Schrödinger was one of the fathers of quantum mechanics. The quantum mechanical wave equation carries his name. It was at the Institute of Advanced Studies in Dublin that he gave a famous series of lectures in 1942, published as a book with the 
ambitious title What is Life? His book contains two key predictions about genetics, one of which turned out to be spectacularly successful, the other became the first, and incorrect, step towards the Central Dogma.

Schrödinger's First Prediction This is the successful one and it concerns the level at which all genetic inheritance could be stored. The information to enable another organism to be created is so vast that it had to be stored at a molecular level. But what kind of molecule could that be? Physicists already knew about the molecular structure of crystals and how that structure could replicate itself by incorporating further similar molecules to grow from a tiny to a large crystal.

That idea could allow the structure to be replicated, but it wouldn't contain much structural data that could be used as information. The data would be only just enough to enable that crystal structure to grow, not to differentiate, as cells do when an embryo grows, into many different forms. A standard crystal, as it grows, just duplicates the same information repeatedly. We could call such duplication periodic. So, he reasoned that the genetic molecule, by contrast, would have to be a-periodic. The data contained in the molecular structure would not be just a repeating sequence, but rather a non-repeating sequence. He called this an aperiodic crystal.

At that time, it was not known what kind of molecule contained the genetic information, but if a one-dimensional molecular thread can be thought of as a crystal, then an aperiodic crystal is quite a good analogical description of what was later found to be DNA. The sequence in DNA contains repeats, but not just an endlessly long repeat. We also know that it must be able to replicate, so a non-repeating replicator is what he predicted would be found. He was correct of course. But it is important to realise that this correct prediction contained the seeds of the incorrect one. The metaphor of a crystal is misleading if the molecules involved never actually form a crystal. As we now know, DNA does not do this. It is not crystalline. It retains its thread-like shape and is carefully wound around special proteins in the chromatin, the histones (Gilbert and Ramsahaye 2005).

Schrödinger's Second Prediction A periodic crystal can replicate simply by forming a template for further molecules of the same type to add themselves endlessly to the growing crystal. Since DNA does not itself exist in crystalline form there is no way for replication to be a self-templating process like the growth of a crystal.

Yet, when cells divide, the DNA does in fact get replicated highly faithfully. The error rate in copying a human genome of 3 billion bases can be as low as 1 error in $10^{10}$ bases. In a genome of length $3 \times 10^{9}$, there would usually be no or perhaps just an occasional single error.

The beginning of the illusion lies in the fact that DNA cannot self-replicate at this degree of accuracy (Noble 2016, p 156; Noble 2018). This part of the analogy with crystal formation is deeply incorrect. Accurate replication can only be performed in a cell with all the cellular error-correcting machinery to reduce an initial error rate of 1 in $10^{4}$ to just 1 in $10^{10}$. Schrödinger did not know that fact. He would have had to add to his analogy between the genetic material and a crystal the assumption that every time the crystal grows an army of other molecules come in as a well-organised system to help it do so. 
The necessity for and the idea of proof-correcting machinery was first proposed by Hopfield (1974) and by Ninio (1975). The technical details of this process are still the subject of active research (see review by Bębenek \& Ziuzia-Graczyk, 2018). But the outlines of the process are clear. Bębenek \& Ziuzia-Graczyk state that

"The accuracy of replication relies heavily on the ability of replicative DNA polymerases to efficiently select correct nucleotides for the polymerization reaction and excise mistakenly incorporated nucleotides using their intrinsic exonucleases. DNA replication is constantly challenged by endogenous and exogenous chemicals, non-canonical DNA structures, and difficult to replicate DNA sequences."

So, the 'army' that carries out the proof-reading and correcting is a set of proteins that can cut and paste and move DNA around. But it only works within the context of the cell as a whole. The proof-correcting accuracy is quite remarkable. It is equivalent to human proof-readers correcting several hundred thousands of mistakes with hardly a single error. Even the great Schrödinger would not have got away with that idea in 1942. Nature took a couple of billion years to perform such a magnificent trick. We now know it was not a trick because, much later than Schrödinger, we have found all those molecules that are orchestrated by living cells to perform the greatest spectacle on earth: the dance of the genes when a cell creates two new cells. To Schrödinger all of this would have seemed like impossibility. Yet it is the reality. This point is important. It beautifully illustrates why I emphasised above that I am not accusing anyone of intentional illusion. Schrödinger really could not have imagined what we now know. Yet it is critical to understanding why the crystal metaphor was misleading. Instead of automatic molecular accretion, each nucleotide has to be carefully shepherded into its correct place.

I conclude therefore that versions of the Modern Synthesis that represent DNA as replicating "like a crystal" (Dawkins 1976, 2016) are incorrect.

\section{Step 2. The Triplet Code}

The DNA sequence is used by organisms to make other molecules. Some of those molecules are the proteins that form ion channels and networks of chemical reactions that enable us to create and store energy, either from sunlight or from food. But the bases of proteins are not the same as the nucleotides that form DNA. They use a very different kind of chemical, called amino acids. Our proteins are made with just 20 different amino acids. Their forms can be almost infinite. This indefinite flexibility resembles that of human languages.

Now, DNA uses just four bases. How can its sequence correspond to a completely different long chemical made from 20 different amino acids? That is achieved by having 3 DNA bases correspond to just one amino acid. Two is not enough. There aren't enough combinations of just 2 bases. Three is actually more than sufficient. There could be more than 20 amino acids, in fact up to 64 (63 coding for amino acids and one triplet acting as a STOP code). Nature has instead settled for the lower number, 
which means that there is redundancy. Several different DNA triplet sequences correspond to the same amino acid. Moreover, the existence of redundancy makes it impossible to specify the complete DNA sequence from a protein sequence. This becomes important when we return to the Central Dogma in step 4. First I will explain how error-correcting is possible. That takes us to the discovery of the double helix.

\section{Step 3. The Double Helix}

An error rate of 1 in 10,000 would have been acceptable when only relatively short DNA or RNA threads of a few thousand bases existed in very early and much simpler forms of life. But a living organism that depends on a sequence as long as 3 billion cannot tolerate such poor replication. Even a cellular army of helpers coming in to rescue the situation would not know what to do if it does not know where the errors are.

It would need to compare the error sequence with a correct one. Nature has discovered precisely how to do that. In organisms like us, there are always two threads. One is a mirror image of the other. The two threads are wound around each other, so forming the double helix (Watson, 1968). They are mirror images of each other through a chemical fact about how the bases interact. The base in one thread most naturally forms a bond with its partner base in the other. $\mathrm{C}$ and $\mathrm{G}$ connect together, so do A and T. A mismatch occurs when this rule is not obeyed. What the error-correcting machinery does is to detect these mismatches and substitute the correct match. There are special proteins - the proof-correcting army referred to earlier - that can cut and paste DNA sequences, just like correcting an error in the paper tapes used in the early valve computers of the kind I was using in the 1960s (Noble 1960, 1962). I fully understand why Jacob and Monod used the term "genetic programme" (Jacob and Monod 1961; see also Peluffo 2015). They wrote: "The programme is a model borrowed from electronic computers. It equates the genetic material with the magnetic tape of a computer." I may be one of the few scientists left who have practical understanding of what they wrote. Paper and magnetic tape forms of storage gave way long ago to hard drives, cloud storage, and so distanced us from what inspired Jacob and Monod's metaphor, even from the fact that it was a metaphor. It is a mistake to represent all biological information as digital. The DNA is not information in that sense when it is being replicated. It is just a chemical sequence that the proof-correcting process laboriously corrects. To that process, it might as well be meaningless data. Furthermore, it is not the only material that is replicated when a cell divides. The rest of the cell structure is best viewed as analogue data that self-templates, and it represents at least as much information to the living organism as the genome (Noble 2017, pp. 114-129). Replication in living systems involves the complete cell. There is no separate replicator independent of its 'vehicle'. That representation of inheritance in evolutionary biology is also incorrect. This is a suitable point also to acknowledge Hoffmeyer's (2002) "Fallacy of Digitalism". As he made clear there is no reason to privilege digital over analogue in understanding living organisms.

\section{Step 4. The Central Dogma}

There are many misunderstandings about what the Central Dogma states and how it should be interpreted. It is therefore important to start from what Francis Crick himself 
wrote. He had two formulations. The earliest, in 1958 (Cobb, 2017), was the simplest. DNA sequences can be translated into RNA sequences which can specify a protein, but the system cannot work in any way at all in the reverse direction. Crick's statement in an article "On protein synthesis" (Crick 1958) was: "The central dogma of molecular biology deals with the detailed residue-by-residue transfer of sequential information. It states that such information cannot be transferred back from protein to either protein or nucleic acid."

Yet, in 1970 the discovery was made of special proteins that can reverse the transcription process. RNAs can be used to form DNAs (that, in any case, was not forbidden by the triplet code), and even more significant, DNAs can be inserted by a cut and paste process into an existing DNA sequence. This discovery is very important since it is the Trojan Horse through which the Central Dogma can be sidestepped. If there had been no cut and paste process, functional reorganisation of the genome would have been impossible.

In 1970, Crick therefore modified his statement of the Central Dogma. He wrote:

"The central dogma of molecular biology deals with the detailed residue-byresidue transfer of sequential information. It states that such information cannot be transferred back from protein to either protein or nucleic acid."

Which can be represented by the following diagram (Fig. 1):

Notice however that even this extended diagram of the Central Dogma is incomplete since it does not include any flow of information from the organism that controls patterns of gene expression, and which initiates or controls insertion of DNA into the genome either directly or following reverse transcription from RNA. Yet, by reverse transcription and cut-and-paste processes in a read-write genome (Shapiro 2017), it becomes possible to transfer sequences, including whole domains corresponding to functional parts of proteins, from one part of the genome to another. Genome sequencing has shown that this must have happened during evolution. The idea that the genome is isolated from any functional influences on the sequences is therefore simply incorrect.

Crick's 1970 restatement was very carefully crafted, I think, in order to save the essential consequences of the original formulation. It is important to ask whether it really succeeds in doing that. To help in answering that question I have italicised two key phrases: "such information" and "from protein". It therefore forbids using sequential information in proteins to specify and make new DNA sequences. As we have already seen, that is unlikely since the triplet code is redundant. There is no way the protein sequence could fully predict the DNA sequence. But Crick was trying to exclude much more than that. It doesn't matter whether the back translation would be exactly the same as the original. If it still specified the same protein sequence, that would do.

I think that in rewriting his statement he was trying to exclude precisely what I think has happened. The control of the genome which Barbara McClintock first discovered (McClintock 1984) in plants, and which James Shapiro confirmed in bacteria, leading to the development of the various processes of natural genetic engineering (Shapiro 2011), has little or nothing to do with sequential information being transferred from a particular protein sequence to a corresponding DNA sequence. 


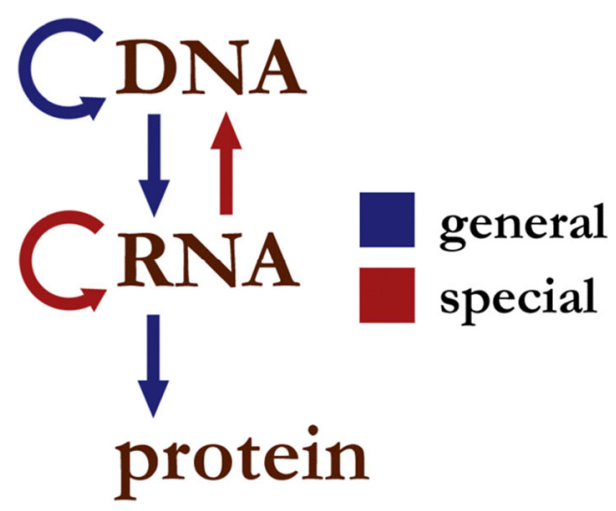

Fig. 1 Central Dogma after discovery of Reverse Transcription. DNA codes for RNA which then codes for proteins (blue arrows). RNA can be reverse transcribed into DNA (upward red arrow). This kind of diagram is often described as defining the information flows in biological systems. But it omits information flows that control gene expression, i.e. transcription factors, methylation and interactions with histones, the nuclear proteins around which DNA is wound. It also omits the use of the molecular mechanism of reverse transcription to reorganise the genome (natural genetic engineering). The circular arrows represent the fact that DNA can also be involved in cut-and-paste modifications of the genome without the involvement of RNA, and that a similar self-templating can occur in RNA. (diagram from https://commons.wikimedia.org/ wiki/File:Centraldogma_nodetails.png)

There seems therefore to be a direct clash between the McClintock and Shapiro's work and the standard interpretations of the Central Dogma. How could these two interpretations possibly be reconciled?

This is the turning point in this article. So far I have outlined what I consider to be the four main illusions of the Modern Synthesis. I now turn to the more constructive task: how to avoid such illusions. How can we recast the language of biology?

\section{Formulation of the Principle of Biological Relativity}

The illusions all depend on giving credence to a one-way form of causation in living organisms. Can that possibly be true? The answer is no, since living organisms are necessarily open systems.

I was struggling with this question when I formulated what I call the principle of biological relativity (Noble 2012). The idea can be viewed as an extension of the general principle of relativity, which is that we should avoid privileging any particular view of the universe. Physicists have applied that principle to speed of movement. All movement is relative to other bodies - there is no privileged position from which to measure speed. And they have applied it to concepts of acceleration and gravity with remarkable results. The outcome is a transformation of our concepts of the universe. There is no centre from which to view everything.

Organisms are part of the universe. The processes that gave rise to them are the very same processes to which the principle of relativity applies. Why then should living systems be an exception to the principle? Specifically, why on earth assume that there is a centre: a privileged level from which the forces that shape living organisms emanate? And why should that be thought to be a molecule, however long, and particularly one that is dead outside living organisms? 
My suspicion was that The Central Dogma makes an assumption that cannot be justified from a relativity perspective. Without fully realising it, precisely that principle had been staring at me ever since my 1960 modelling of heart rhythm. The reason I was successful in that work is that there isn't a separate oscillator driving the pacemaker. It drives itself. If you isolated all the components, there would be no oscillator. Yet each differential equation describing any one of those components would be just the same. What would change are the constraints provided by the cell itself when those components are part of a living cell.

Constraints? Where do those appear in any differential equations? They arise from a necessary mathematical fact: the equations have no solution unless you specify the initial and boundary conditions. Those form the constraints in such a mathematical model. They arise from the organisation of the higher level. The principle therefore achieves two necessary criteria: no privileged level of causation, and the top-down form (the constraint) is just as necessary as the mechanical upward form. The top-down causation is attributable to formal organisation, within which the bottom-up dynamic causation is constrained to occur.

To return to the issue of natural genetic engineering, it has to do rather with the overall control of genome function by the cell and organism as a whole, leading to massive reorganisation of genomes and the karyotype (Heng 2019) when organisms experience environmental stress. It is not about molecular level templates, or the gradual accumulation of point mutations in them. It is extremely complex functional networks of proteins, lipids, transmitters and metabolites that orchestrate the processes by which control of the genome and natural genetic engineering can occur. A multilevel view of biology that avoids necessarily privileging any level also avoids the relevant linguistic traps.

This is a suitable point at which to emphasise that the environment also is a complex and continuously changing influence. It has itself been created by the evolution of organisms. All the arrows in Fig. 2 are therefore also continually evolving and there must also be an upward arrow from the organism to the environment (the open black arrow in Fig. 2). This is form of interaction is also a feature of the Extended Evolutionary Synthesis in relation to Niche construction and Evo-Devo.

\section{Step 5. "The Weismann Barrier is now embodied by the Central Dogma"}

One of the central ideas of the Modern Synthesis is that evolution is a completely blind process. This idea is beautifully expressed in Dawkins' (1986) The Blind Watchmaker. One of the consequences of the principle of biological relativity is that the idea is not correct. This was shown in an article entitled Was the Watchmaker Blind? Or was she One-eyed? (Noble and Noble 2017) (Noble \& Noble, 2018). After we had explained why the Weismann Barrier could not be absolute, we encountered the argument from a referee that "The Weismann Barrier is now embodied by the Central Dogma."

This is a widespread illusion, commonly found on the Internet. It is an understandable one. The triumph of twentieth century molecular biology is frequently represented as vindicating neo-Darwinism. It can't possibly do that. The Weismann Barrier is a statement about cells, specifically the supposed isolation of 


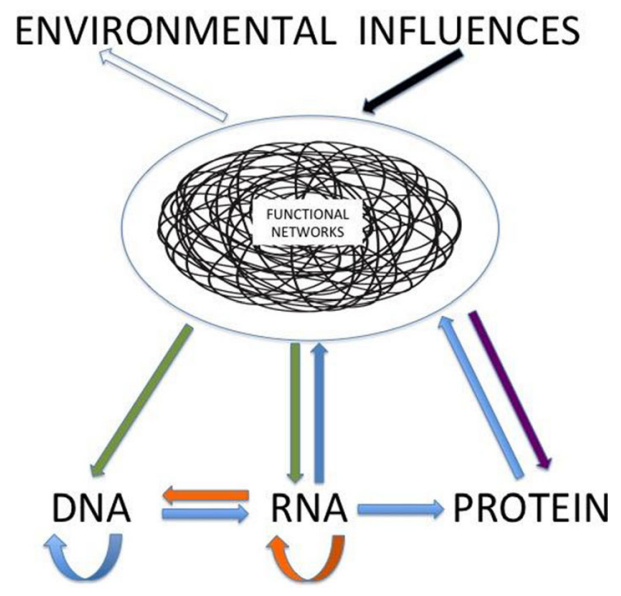

Fig. 2 Central Dogma diagram embedded in interactions with the system of functional causal networks. This diagram adds to Fig. 1 the information flows (green arrows) that control gene expression, i.e. transcription factors, methylation and interactions with histones. The green arrows also represent the use of the molecular mechanisms of reverse transcription and cut-and-paste processes to reorganise the genome (natural genetic engineering). The significance of other arrows: Black arrow represents environmental influences on the functional networks. Open black arrow represents the influence of the organism on the environment. Purple arrow represents the influence of network structure on protein folding and function. Upward blue arrows represent the fact that RNAs and proteins form parts of the networks, as catalysts, transporters, structures, and communication pathways. (Diagram created by the author for this article. The network image at the centre of the oval is taken with enhanced licence permission from https:/www.shutterstock.com/image-vector/chaostangle-circle-doodle-line-chaotic-1055187698)

the sperm and egg cells. The Central Dogma is a statement about molecules. From the viewpoint of a molecule a cell is as vast as the area of a country like England. Inheritance at the cellular level, including the intricate architecture, is vastly more than inheritance of DNA. To conflate molecular and cellular inheritance is a deeply confusing illusion.

I have explained the fourth illusion at length, step by step historically, because I believe it has strongly misled biological science for most of 80 years since Julian Huxley's book Evolution: The Modern Synthesis and Erwin Schrödinger's lectures on What is Life?, both dated 1942 although Schrödinger's book came out in 1944. I believe this article is the first time that all the relevant (mis-)steps have been laid out in a step-by-step logical argument. Once again, I also acknowledge the insights of Hoffmeyer (2002), Even the title of that paper says it all: "The Central Dogma: A Joke that Became Real." Hoffmeyer's argument, however, rests on a different basis, when he writes

"there is nothing that "flows" from DNA to RNA to protein. Instead what goes on is semiosis, i. e. the organized cellular system interprets the digitally coded messages in the chromosomes according to the changing contexts in which the cell or the organism finds itself."

Of course the cell itself, through its elaborate proof-correcting processes, ensures that the inherited sequences are interpretable and so become the basis of a form of semiosis. 


\section{Previous Work}

But, I am not the first to point out some of the key facts. The vast difference of up to a million fold between the 'natural' error rate when DNA is first copied and when it is proof-corrected by the cell has been known for a long time (see Li et al. 2014). It is the reason why reducing proof-correcting efficiency can enable the immune system to rapidly generate millions of new immunoglobulins (Odegard and Schatz 2006), and that bacteria can hypermutate to evolve rapidly in response to stress (Bos et al. 2015). The fact that stochasticity is an important feature of cells and tissues and is used as cellular-level selection in development has been pointed out long ago by Kupiec (1983, 2009, 2020).

I acknowledge this previous work, and also emphasise again that I am not accusing anyone of the intentional creation of illusions. As a well-known critic of neoDarwinism I have sometimes been accused of not recognising the work of neoDarwinists. On the contrary, I have openly and fulsomely praised the founders of the Modern Synthesis. To quote Dance to the Tune of Life:

"The scientists who developed the Modern Synthesis were brilliant and they were amongst the most influential scientists of the twentieth century.

They formulated the best hypothesis they could that would combine the observations and insights of Darwin and Wallace on the role of natural selection with the discoveries of Mendel and the idea of the Weismann barrier on genetics. As a hypothesis, it was very successful. The study of the genetics of populations was transformed and became a rigorously mathematical discipline.

The Modern Synthesis also fitted extremely well with the early discoveries of molecular biology." (Noble 2016, p 136).

I wrote that five years ago. This article shows that the last sentence is no longer strictly correct. I would now write: "The Modern Synthesis was perceived to fit extremely well with the early discoveries of molecular biology."

I have also frequently referred to the brilliant and enjoyable writing of neo-Darwinism's great populariser, Richard Dawkins. We all can and should praise great predecessors for what they achieved, but that doesn't entail necessarily agreeing with all they say.

\section{The Importance of Moving Away from Gene-Centric Theories of Evolution}

How much do scientific illusions matter? Is the task of unraveling them important merely from a semantic viewpoint? I believe the answer to that question is firmly no.

Gene-centrism is an important legacy of the Modern Synthesis, which has had influence way beyond the subject of evolutionary biology including clinical medicine, economics, politics and sociology. The peak of this influence in the medical sciences was the representation of the genome as the "Book of Life", the sequencing of which would lead within a decade or two to cures for the major diseases. Instead, through genome-wide sequencing, we have encountered a failure of gene-centrism. Most 
association levels are small (Boyle et al. 2017), so much so that we can be sure that such methods do not reveal causation (Noble and Noble 2020). The regulatory networks (Fig. 2) effectively buffer organisms from most genetic changes.

I have highlighted the importance of moving on from gene-centrism in relation to economics and related studies in another recent article (Lee et al. 2019).

\section{Relevance to Biosemiotics: A Bridge between Disciplines}

As I noted in the Introduction, biosemiotics is traditionally not so much concerned with the uses (and misuses) of human language, as with prelinguistic meaning-making in organisms through the production and interpretation of signs. What then is the relevance of linguistic illusions to biosemiotics and vice-versa? As a biological scientist trained outside the discipline of biosemiotics, my ideas on the relevance of what I have discussed in this article to biosemiotics will inevitably be just a few hints that others much more professional than me might take up.

Humans evolved of course from other species. It would be extremely surprising if insights from the study of illusions in human language did not have relevance to the study of meaning-making in other organisms, and vice-versa (Filippi 2015). This is particularly true for unintended illusions. Why can they become so strong? Many of the biological facts I have noted in this article have been known for many years. Yet the illusions that they undermine have nevertheless been strongly maintained as part of the orthodoxy of evolutionary biology.

One possible answer to that paradox is the wide variety of processes generating choice biases in both humans and animals. In their classic review of the evolutionary roots of human decision-making, Santos and Rosati (2015) show how "understanding patterns of decision making in other primates can help identify the sorts of cognitive mechanisms that underlie human choice biases." One of the important psychological phenomena they investigate is the endowment effect, in which an organism overvalues a good that they own compared to one they do not. Both humans and other animals do this. In science it becomes the reluctance to abandon a cherished theory. I know that phenomenon well because I have had to go through it several times in my own physiological research (Noble 2020).

If we follow Ginsburg and Jablonka's (2019) arguments for attributing conscious action to many other organisms capable of unlimited associative learning, then those organisms must also be capable of intended or unintended illusions. I am assuming here, of course, that conscious meaning is a prerequisite of the creation of illusions. I think that biosemiotics could make valuable contributions to this issue. As an example, through understanding the perspective (the Umwelt) of an animal like the wolf (Tønnessen 2010) we may come to understand its possible use of illusory behavior in predator-prey interactions and in signaling within social networks. Organisms capable of anticipatory behavior surely must use such tactics in successful hunting, just as conscious prey must do so to avoid them. I suspect that this must be what Tønnessen has in mind when he refers to "the naïvety of prey". They become less naïve precisely through developing anticipation of the diversionary signs from predators.

Of course, I am not suggesting that all illusory signs in organisms are intended. The illusory mimicry displayed by many organisms may well not be consciously intended 
by the organism displaying it. Recall that Darwin attributed the beauty of male birds to the conscious sexual selection by females. Are peacocks themselves aware of their beauty? - they strut as though they are. Well, I had better leave that to the biosemioticians to answer, if indeed it can be.

\section{Relevance of Umwelt Theory}

Tønnessen (2015b) has also addressed the application of Umwelt theory to human language in which he argues that "language is not external to Umwelt, but internal to it. Language changes the human Umwelt not by escaping or sidelining it, but by fundamentally transforming it." This gets to the core of what I think happened in the development of the illusions of the Modern Synthesis between 1940 and the end of the last century. Language was crafted in creating a coherent model of how organisms work and how they depend on and interact with their environment. In a biosemiotic context we could call it the Umwelt, the mind-set on the nature of the environmentorganism interaction, of the Modern Synthesis. That corresponds with what I wrote near the beginning of this article: "all parts of the discourse encourage the use and acceptance of the other parts which is why it is difficult to break out from the compelling model that it forms of the world."

The Modern Synthesis in its various forms, but particularly strongly in the founding form of a synthesis between the Weismann Barrier and Mendelian Genetics, represents the organism-world relationship in a limited way. It views the environment as the passive filter of natural selection rather than seeing organisms as an essential and active driver of the environment. As I have noted earlier, both the EES and the EIS seek to correct this limitation. The reason I go further than the EES is that I also show that the Modern Synthesis has been undermined, not supported, by molecular biology. It doesn't make sense to retain a theory that has been so fundamentally undermined on its central assumptions, i.e. the Weismann Barrier, the isolation of the genome from the organism and the environment, and the exclusion of Lamarckian forms of inheritance, since these were the central motivations of the Modern Synthesis (Huxley 1942). As I have already emphasized, the fact that molecular biology does not confirm these assumptions was not realized in the $50 \mathrm{~s}, 60 \mathrm{~s}$ and $70 \mathrm{~s}$ when the incorrect interpretation of molecular biology held sway. The need for extensive cellular proof-correcting processes only began to appear in the mid 1970s (Hopfield 1974; Ninio 1975), and the remarkable processes by which they could be controlled to allow hyper-mutation to occur only appeared in 2012 (Saribasak and Gearhart 2012).

The 2015 volume on Biosemiotic Perspectives on Language and Linguistics contains many other relevant chapters and declares its overall aim "to establish a new relationship between linguistics and biology as based on shared semiotic foundation." I welcome that aim. The creation of such a bridge is the direct subject of a previous article in this journal, Biosemiotics (Barbieri 2010).

Hendlin (2020) also specifically draws the connections between biosemiotics and studies of our own species in his article significantly titled "The human turn in biosemiotics". He concludes a fascinating piece with the conclusion "By getting into the business of attending to especially nonsymbolic biosemiosis applied to human psychology and culture, our discipline can provide a much needed bridge between 
findings in the natural sciences and policy implications based on how these effect human functioning and behavior."

I think therefore that I may be knocking at an open door in accepting the invitation of the Editors of Biosemiotics to contribute a Target Article. I hope it will provoke others to pitch in and develop or counter my arguments. A collaboration between philosophers and scientists is necessary to tidy up the language of biology and make it fit for the twenty-first century.

Acknowledgements Denis Noble is a member of the Project "Foundations of Value and Values" at the Said Business School of the University of Oxford and acknowledges valuable input from the members of that group. I also thank Anthony Kenny, and two referees, for valuable criticisms of an early draft.

Open Access This article is licensed under a Creative Commons Attribution 4.0 International License, which permits use, sharing, adaptation, distribution and reproduction in any medium or format, as long as you give appropriate credit to the original author(s) and the source, provide a link to the Creative Commons licence, and indicate if changes were made. The images or other third party material in this article are included in the article's Creative Commons licence, unless indicated otherwise in a credit line to the material. If material is not included in the article's Creative Commons licence and your intended use is not permitted by statutory regulation or exceeds the permitted use, you will need to obtain permission directly from the copyright holder. To view a copy of this licence, visit http://creativecommons.org/licenses/by/4.0/.

\section{References}

Barbieri, M. (2010). On the origin of language A bridge between biolinguistics and biosemiotics. Biosemiotics, 3, 201-223.

Bębenek, A. \& Ziuzia-Graczyk, I. (2018). Current Genetics. 64:985-996. https://doi.org/10.1007/s00294018-0820-1.

Bos, J., Zhang, Q., Vyawahare, S., Rogers, E., Rosenberg, S. M., \& Austin, R. (2015). Emergence of antibiotic resistancefrom multinucleated bacterial filaments. Proc. Natl. Acad. Sci. USA, 112, 178-183.

Boyle, E. A. L., Li, Y. I., \& Pritchard, J. K. (2017). An expanded view of complex traits: From polygenic to omnigenic. Cell, 169, 1177-1186.

Chen, H., Yang, P., Chu, X., Huang, Y., Liu, T., Zhang, Q., Li, Q., Hu, L., Waqas, Y., Ahmed, N., \& Chen, Q. (2016). Cellular evidence for nano-scale exosome secretion and interactions with spermatozoa in the epididymis of the Chinese soft-shelled turtle, Pelodiscus sinensis. Oncotarget, 7(15), 19242-19250.

Churchill, F.B. 2015. August Weismann: Development, heredity, and evolution. Harvard University Press.

Cobb, M. (2017). 60 years ago, Francis Crick changed the logic of biology. PLoSBiol, 15(9), e2003243.

Corning, P. (2020). Beyond the modern synthesis: A framework for a more inclusive biological synthesis. Progress in Biophysics and Molecular Biology., 153, 5-12.

Cossetti, C., Lugini, L., Astrologo, L., Saggio, I., Fais, S., \& Spadafora, C. (2014). Soma-to-germline transmission of RNA in mice xenografted with human tumour cells: Possible transport by exosomes. PLoS One, 9(7), e101629.

Coyne, J. A. (2009). Why evolution is true. Oxford: Oxford University Press.

Coyne, J. A. (2014) What scientific idea is ready for retirement? https://www.edge.org/response-detail/25381

Crick F.H.C. (1958). On protein synthesis. Symp Soc Exp Biol.12:138-163. pmid:13580867.

Crick, F. H. C. (1970). Central dogma of molecular biology. Nature, 227, 561-563.

Darwin, C. (1859). On the Origin of Species by Means of Natural Selection, or the Preservation of Favoured Races in the Struggle for Life 1859. London: John Murray.

Darwin, C. (1868). The variation of animals and plants under domestication. London: John Murray.

Darwin, C. (1871). The descent of man, and selection in relation to sex (p. 1871). London: John Murray.

Dawkins, R. (1976). The selfish gene. Oxford: OUP.

Dawkins, R. (2016). The Selfish Gene, 40th anniversary edition. Oxford: OUP.

Dawkins, R. (1981). In defence of selfish genes. Philosophy, 56, 556-573. 
Dawkins, R. 1986. The blind watchmaker. Norton.

Edelstein, L.R., Smythies, J.R., Quesenberry, P.J. \& Noble, D (Eds) 2019. Exosomes: A Clinical Compendium. Elsevier.

Filippi, P. (2015). Before babel: The evolutionary roots of human language. In K. Kull \& S. J. Cowley (Eds.), Velmezova, E (pp. 191-204). Biosemiotic Perspectives on Language and Linguistics: Springer.

Futuyma, D., \& Kirkpatrick, M. (2018). Evolution. 4th Edition 2018: Sinaur Associates and Oxford University Press.

Gilbert, N., \& Ramsahaye, B. (2005). The relationship between chromatin structure and transcriptional activity in mammalian genomes. Briefings in functional genomics and proteomics., 4, 129-142.

Ginsburg, S., \& Jablonka, E. (2010). The evolution of associative learning: A factor in the Cambrian explosion. Journal of Theoretical Biology, 266, 11-20.

Ginsburg, S. \& Jablonka, E. (2019). The evolution of the sensitive soul. Learning and the Origins of Consciousness. MIT Press.

Gluckman, P., \& Hanson, M. (2011). The fetal matrix: Evolution, development and disease. Cambridge: Cambridge University Press.

Heijmans, B. T., Tobi, E. W., Stein, A. D., Putter, H., Blauw, G. J., Susser, E. S., Slagboom, P. E., \& Lumey, L. H. (2008). Persistent epigenetic differences associated with prenatal exposure to famine in humans. PNAS, 105, 17046-17049. https://doi.org/10.1073/pnas.0806560105.

Hendlin, Y.H. 2020. The human turn in biosemiotics. In Lackova, L. Rodriguez, C.J. \& Kull, K. 2020. Gatherings in Biosemiotics XX. University of Tartu Press. Pp 50-71.

Heng, H. (2019). Genome Chaos. Rethinking Genetics, Evolution and Molecular Medicine. Elsevier.

Hoffmeyer, J. (2002). The central dogma: A joke that became real. Semiotica, 138(1/4), 1-13.

Hopfield, J. J. (1974). Kinetic proofreading: A new mechanism for reducing errors in biosynthetic processes requiring high specificity. Proceedings. National Academy of Sciences. United States of America, 71(10), 4135-4139. https://doi.org/10.1073/pnas.71.10.4135.

Huxley, J. S. (1942). Evolution. Allen and Unwin: The Modern Synthesis.

Jacob F., Monod J., 1961. Genetic regulatory mechanisms in the synthesis of proteins. J. Mol. Biol. 3: 318356. [PubMed] [Google Scholar].

Kull, K. (2018). Choosing and learning: Semiosis means choice. Sign Systems Studies, 46, 452-466.

Kupiec, J.-J. (1983). A probabilistic theory for cell differentiation, embryonic mortality and DNA c-value paradox. Speculations in Science and Technology, 6, 471-478.

Kupiec, J.-J. (2009). The origin of individuals. World Scientific.

Kupiec, J.-J. (2020). A probabilistic theory for cell differentiation, embryonic mortality and DNA cvalue paradox. Organisms. Journal of Biological Sciences, 4(1), 8-10. https://doi.org/10.13133/ 2532-5876/16955.

Lakoff, G., \& Johnson, M. (1980). Metaphors we live by. Chicago: University of Chicago Press.

Lavitrano, M., Busnelli, M., Cerrito, M. G., Giovannoni, R., Manzini, S., \& Vargiolu, A. (2006). Spermmediated gene transfer. Reproduction, Fertility and Development, 18, 19-23.

Lee, Y. H., Mayer, C., Noble, D., \& Vines, D. (2019). Against the microfoundation hegemony: Cooperation in biology, business and economics. Theoretical Biology Forum, 112, 53-77.

Li, Z., Woo, C. J., Iglesias-Ussel, M. D., Ronai, D., \& Scharff, M. D. (2014). The generation of antibody diversity through somatic hypermutation and class switch recombination. Genes \& Development, 18, 1-11.

Menzel, Randolf (2003). Creating presence by bridging between the past and the future: The role of learning and memory for the organization of life. In: Kühn, Reimer; Menzel, Randolf; Menzel, Wolfram; Ratsch, Ulrich; Richter, Michael M.; Stamatescu, Ion-Olimpiu (eds.), Adaptivity and Learning: An Interdisciplinary Debate. Berlin: Springer, 59-70.

McClintock, B. (1984). The significance of responses of the genome to challenge. Science, 226, 792-801.

Ninio, J. (1975). Kinetic amplification of enzyme discrimination. Biochimie., 57(5), 587-595. https://doi.org/ 10.1016/S0300-9084(75)80139-8.

Noble, D. (1960). Cardiac action and pacemaker potentials based on the Hodgkin- Huxley equations. Nature, $188,495-497$.

Noble, D. (1962). A modification of the Hodgkin-Huxley equations applicable to Purkinje fibre action and pacemaker potentials. The Journal of Physiology, 160, 317-352.

Noble, D. (2012). A theory of biological relativity. Interface Focus, 2, 55-64.

Noble, D. (2016). Dance to the tune of life. Biological Relativity. Cambridge: Cambridge University Press.

Noble, D. (2017). Digital and analogue information in organisms. In S. I. Walker, P. C. W. Davies, \& G. F. R. Ellis (Eds.), From matter to life: Information and causality. Cambridge: CUP. 
Noble, D. (2018). Central Dogma or Central Debate? Physiology, 33, 246-249. https://doi.org/10.1152/ physiol.00017.2018.

Noble, D. (2019). Exosomes, Gemmules, pangenesis and Darwin, in (Edelstein, L.R., Smythies, J.R., Quesenberry, P.J. \& Noble, D (Eds) Exosomes: A Clinical Compendium. Elsevier. Pp 487-501.

Noble, D. (2020). The surprising heart revisited: An early history of the funny current with modern lessons. Progress in Biophysics and Molecular Biology. https://doi.org/10.1016/j.pbiomolbio.2020.07.010.

Noble, D. \& Hunter, P. (2020). How to link genomics to physiology through epigenomics. Epigenomics, 12, 285-297.

Noble, R., \& Noble, D. (2017). Was the watchmaker blind? Or was she one-eyed? Biology, 6, 47. https://doi. org/10.3390/biology6040047.

Noble, R., \& Noble, D. (2018). Harnessing stochasticity. How organisms make choices. Chaos, 28, 106309. https://doi.org/10.1063/1.5039668.

Noble, R., Tasaki, K., Noble, P. J., \& Noble, D. (2019). Biological relativity requires circular causality but not symmetry of causation: So, where, what and when are the boundaries? Front. Physiol, 10, 827.

Noble, R., \& Noble, D. (2020). Can reasons and values influence action: How might intentional agency work physiologically? Journal of the General Philosophy of Science. https://doi.org/10.1007/s10838-02009525-3.

Normandin, S. \& Wolfe, C.T. 2013. Vitalism and the scientific image in post-enlightenment life science, 1800-2010. Springer Science and Business Media.

Odegard, V. H., \& Schatz, D. G. (2006). Targeting of somatic hypermutation. Nat. Rev. Immunol., 8, 573-583.

Peluffo, A. E. (2015). The "Genetic Program": Behind the Genesis of an Influential Metaphor. Genetics, 200, 685-696. https://doi.org/10.1534/genetics.115.178418.

Pigliucci, M \& Müller, G. (2010) Evolution: The extended synthesis. MIT Press.

Rechavi, O. et al. (2014). Starvation-Induced Transgenerational Inheritance of Small RNAs in Caenorhabditis. elegans. Cell, 158:2 (277-287). https://doi.org/10.1016/j.cell.2014.06.020.

Santos, L.R. and Rosati, A.G. (2015). The evolutionary roots of human decision making, Ann. Rev. Psychol. 66, 321-347 (2015).

Saribasak, H., \& Gearhart, P. (2012). Does DNA repair occur during somatic hypermutation? Seminars in Immunology, 24, 287-292.

Shapiro, J. A. (2011). Evolution: A view from the $21^{\text {st }}$ century. Upper Saddle River: Pearson Education Inc.. Shapiro, J. A. (2017). Biological action in read-write genome evolution. Interface Focus, 7, 20160115.

Shapiro, J. A., \& Noble, D. (2021). The post-modern synthesis movement in organismal evolution. Progress in Biophysics and Molecular Biology In press.

Simmers, J. (2016). The Neuroethology of predation and escape. Oxford: Wiley.

Spadafora, C. (2018). The "evolutionary field" hypothesis. Non-Mendelian transgenerational inheritance mediates diversification and evolution. Progress in Biophysics and Molecular Biology, 134, $27-37$.

Tønnessen, M. (2010). Wolf land. Biosemiotics, 3, 289-297.

Tønnessen, M. (2015a). The biosemiotic glossary project: Agent, agency. Biosemiotics, 8, 125-143.

Tønnessen, M. (2015b). Umwelt and language. In Velmezova, E., Kull, K., Cowley, S.J. (Eds) Biosemiotic Perspectives on Language and Linguistics. Springer. Pp. 77-96.

Waddington, C. 1957. 2014. The strategy of the genes. London: Allen and Unwin.

Watson, J.D. 1968. The double Helix. Weidenfeld and Nicholson.

Winters, A. M. (2018). Introduction: A structural and historical approach to understanding advancements in evolutionary theory. Biosemiotics., 11, 167-180.

Publisher's Note Springer Nature remains neutral with regard to jurisdictional claims in published maps and institutional affiliations. 